\title{
Holistic simulation of wind turbines with fully aero-elastic and electrical model
}

\author{
Marcus Wiens $^{1}$ (D) - Sebastian Frahm ${ }^{1} \cdot$ Philipp Thomas $^{1} \cdot$ Shoaib Kahn ${ }^{1}$ \\ Received: 30 November 2020 / Accepted: 13 March 2021 / Published online: 30 April 2021 \\ (c) The Author(s) 2021
}

\begin{abstract}
Requirements for the design of wind turbines advance facing the challenges of a high content of renewable energy sources in the public grid. A high percentage of renewable energy weaken the grid and grid faults become more likely, which add additional loads on the wind turbine. Load calculations with aero-elastic models are standard for the design of wind turbines. Components of the electric system are usually roughly modeled in aero-elastic models and therefore the effect of detailed electrical models on the load calculations is unclear. A holistic wind turbine model is obtained, by combining an aero-elastic model and detailed electrical model into one co-simulation. The holistic model, representing a DFIG turbine is compared to a standard aero-elastic model for load calculations. It is shown that a detailed modelling of the electrical components e.g., generator, converter, and grid, have an influence on the results of load calculations. An analysis of low-voltage-ride-trough events during turbulent wind shows massive increase of loads on the drive train and effects the tower loads. Furthermore, the presented holistic model could be used to investigate different control approaches on the wind turbine dynamics and loads. This approach is applicable to the modelling of a holistic wind park to investigate interaction on the electrical level and simultaneously evaluate the loads on the wind turbine.
\end{abstract}

\section{Ganzheitliche Simulation von Windkraftanlagen mit aero-elastischem und elektrischem Modell}

\section{Zusammenfassung}

Die Anforderungen an Windenergieanlagen bei der Auslegung steigen angesichts des hohen Anteils an erneuerbaren Energien im öffentlichen Stromnetz. Ein hoher Anteil an erneuerbaren Energien schwächt das Netz und Netzstörungen werden wahrscheinlicher, die zu einer zusätzlichen Belastung der Windenergieanlage führen. Der Standard bei der Auslegung von Windenergieanlagen sind Lastberechnungen mit aero-elastischen Modellen. Die Komponenten des elektrischen Systems sind in der Regel nicht Teil dieser aero-elastischen Lastrechnungsmodelle und daher ist die Auswirkung von detaillierten elektrischen Modellen auf die Lasten nicht eindeutig. In diesem Artikel wird der Aufbau eines ganzheitlichen Windenergieanlagenmodells durch die Kombination eines aero-elastischen Modells und eines detaillierten elektrischen Modells vorgestellt. Dieses ganzheitliche Modell einer DFIG Wind Turbine wird mit einem aero-elastischen Standardmodell für Lastberechnungen verglichen. Es wird durch Co-Simulationen gezeigt, dass eine detaillierte Modellierung der elektrischen Komponenten, z.B. Generator, Umrichter und Netz, einen Einfluss auf die Ergebnisse der Lastberechnungen hat. Eine Analyse von Low-Voltage-Ride-Through Ereignissen bei turbulentem Wind zeigt einen massiven Anstieg der Lasten im Antriebsstrang und Auswirkungen auf die Turmlasten. Darüber hinaus könnte das vorgestellte ganzheitliche Modell für die Untersuchung verschiedener Regelungsansätze in Bezug auf die Dynamik und die Lasten der Windenergieanlage verwendet werden. Dieser Ansatz eignet sich für die Modellierung eines ganzheitlichen Windparks, um die Interaktion auf der elektrischen Ebene zu untersuchen und gleichzeitig die Lasten auf der Windenergieanlage zu bewerten.

Marcus Wiens

marcus.wiens@iwes.fraunhofer.de

1 Fraunhofer IWES, Am Luneort 100, 27572 Bremerhaven, Germany

\section{Introduction}

The increasing demand of renewable energy leads to the development of larger wind turbines with a high rated power output. These large structures experience massive loads 
from incoming wind and the electrical grid, which are accounted for in the design of the wind turbine by load calculations with aero-elastic models. Additionally, a grid with high renewable energy content is considered as less stable and faults occur more often. These increased requirements add more challenges to the design of wind turbines.

In the design of wind turbines, the dynamics and resulting loading from the aero-elasticity and from the power electronics are considered separately. In the last update of the IEC standard from 2019 [1], an additional design load case (DLC) was added to include low voltage ride through (LVRT) events in the load calculation. But it is not specified, how the LVRT event shall be simulated and how the electrical system should be modeled. From the design process, the actual effect of fast generator dynamics and interaction with the public grid on the loading of a wind turbine is unclear and requires expensive measurement on prototypes in the field. This standard design process adds unknown level of uncertainty to ultimate and fatigue loads and thus on the expected life of the wind turbine.

The state of the art for Co-Simulations is described in [2]. This method is mainly used in the field of automotive and electricity distribution research, but less found in the field of wind energy science.

A modelling approach of holistic wind turbines with respect to the generator and gear box model is presented in [3]. This study was focused on the modelling of various types of wind turbines and the effects of the grid on the wind turbine and vice versa. Additionally, the impact on the gearbox model and damping controllers for the drive train are investigated for constant and sinusoidal wind speeds. Turbulent wind and other wind turbine components are not investigated.

A holistic $2.5 \mathrm{MW}$ doubly fed induction generator (DFIG) model is described in [4]. The model consists of a DNV-GL Bladed model for the mechanical part and a Matlab Simulink model for the electrical part. The models are connected via TCP/IP protocol. This model is validated according to measurements of a three-phase dip with a residual voltage of $20 \%$. In [5] two holistic models of DFIG and direct coupled induction machines are shown. For both models the software NREL Fast is used for mechanical and Matlab Simulink for the electrical part. With the direct coupled induction machine, the tower shadow effect is simulated. The DFIG model is used for two and three phase faults in a strong and weak grid condition.

A state space model approach for the electrical and mechanical components of wind turbines is presented in [6]. The drivetrain is represented by an elastic model, but the tower and rotor blade are rigid models. High oscillation of drivetrain loads is shown by simulations of wind turbine start up and wind gusts. A suggestion is made to improve the modelling fidelity by using elastic models for the tower and rotor blades. Furthermore, a wind park simulation is presented in [7]. Using generated turbulent wind fields combined with simple wake models describe the aerodynamic interaction of wind turbines. The aerodynamics of wind turbine are addressed by look up tables for the power and thrust coefficient. Structural dynamics are modelled by two and three-mass models, which is a lower level of detail than for common aero-elastic load simulations.

In this paper, an investigation of the effects of a detailed electrical model on the result of load calculations in a holistic modelling approach is presented. A 2.5 $\mathrm{MWDFIG}$ wind turbine is simulated in turbulent wind and extreme operating gusts with a simultaneous grid fault. The wind turbine is modelled by an aero-elastic model, which allows for elastic tower, rotor blade and drivetrain. Furthermore, the electrical drive train is represented by an electromagnetic transient (EMT) model.

\section{Holistic wind turbine model}

In this approach the holistic wind turbine model consists of four main components. First, there is the aero-elastic model of the wind turbine, which determine the interaction of the wind turbine with a wind field. A wind turbine controller regulates the pitch angle and the generator torque setpoint to ensure stable and automated operation. The electrical model describes the mechanical interaction of the drivetrain with the generator and the response of the generator to the electrical grid and vice versa. The DFIG is controlled by a converter. The holistic wind turbine model approach is visualized in Fig. 1.

All subcomponents are explained in more detail in the following subsections. The whole model is built in Matlab Simulink, similar to the modelling approach in [3]. A fixed time step solver is used. Sub models are calculated with individual fixed time steps and solvers. The wind turbine has a rated power of $2.5 \mathrm{MW}$ and an elastic drive train model. A time step of $200 \mathrm{~Hz}$ is chosen for ODE1 with RungeKutta algorithm for inline integration [8] to increase simulation speed. The wind turbine controller runs at $100 \mathrm{~Hz}$ and is solved by ODE1.

The electromagnetic transient model includes the double fed induction generator, the converter, a transformer, and the grid. This model is modelled in Simulink and SimPowerSystems and is solved with an ODE2 algorithm. Furthermore, the electrical components are simulated at $50 \mathrm{kHz}$ and the converter controllers at $2.5 \mathrm{kHz}$.

The different time steps for each model are necessary since the dynamics of the electrical model are way faster than those of the wind turbine. Additionally, the simulation time can be reduced in this way. All signals between sub- 
Fig. 1 Holistic modelling scheme of a wind turbine with detailed electrical model and connection to the public grid

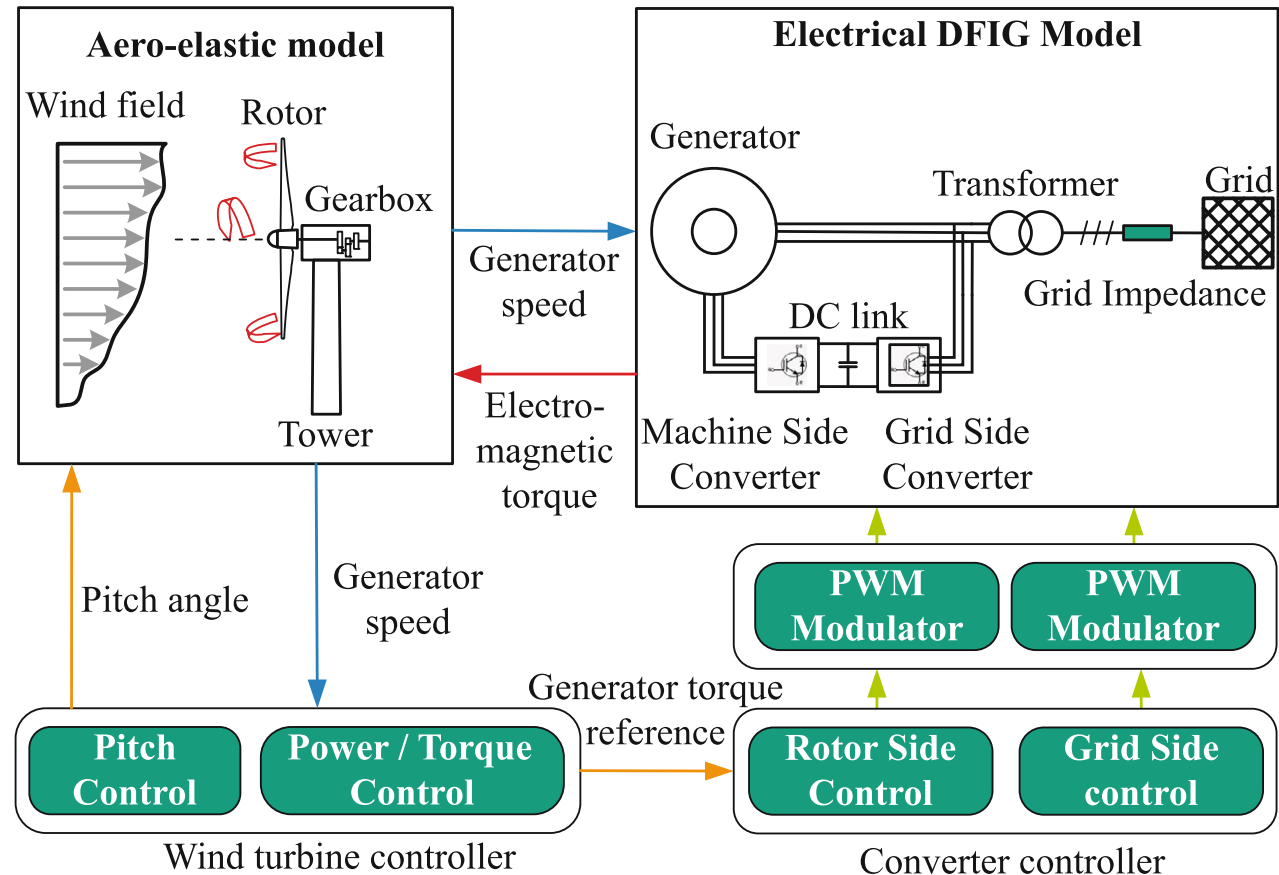

Converter controller models are transmitted by Rate-Transition blocks, which manage the signal flow between different time scales.

For more detail about the underlying equations, it is referenced to the cited references, as a full presentation of all equations is beyond the scope of this paper.

\subsection{Aero-elastic wind turbine model}

The real-time load simulation model MoWiT $[9,10]$ couples physical models for aerodynamics, structural dynamics, hydrodynamics and control and computes them in the time domain. This computational model is developed by Fraunhofer IWES and primarily used for load analysis of (offshore floating [11]) wind turbines as well as for automated simulation [12] and optimization [13]. Further, MoWiT has been in productive operation as a virtual rotor [14] in the Dynamic Nacelle Laboratory (DyNaLab) [15] and [16] for several years now.

MoWiT is programmed with the object-oriented modelling language Modelica. Each major mechanical component of the wind turbine such as the rotor, the nacelle, the tower, the environmental conditions, and the wind turbine control is implemented as a single object. In essence, MoWiT uses a multi-body approach to model the interaction between the individual structural components. The major structural components like the rotor blades and the tower are modelled as flexible bodies using modal reduced, anisotropic beam elements where the superposed eigenmodes represent the elastic degrees of freedom [17].

The aerodynamics are computed at several points along each rotor blade using an unsteady implementation of the so-called Blade-Element-Momentum Theory (BEM). The wind speed used in the aerodynamics can be deterministic or stochastic and accounts for horizontal and vertical inclination, sheer, and tower shadow [10]. The strong coupling between aerodynamics and structural elasticity, called aeroelasticity, ensures a realistic computation of the rotor dynamics. An elastic drivetrain model connects the rotor with the generator, which is modelled by a rotational two-mass spring-damper system. The modelling approach of MoWiT is state-of-the-art in wind turbine load analysis.

The model parameters are obtained from down scaling of the NREL $5 M W$ wind turbine [18] to $2.5 M W$. In detail, the rotor diameter is set to $100 \mathrm{~m}$ and the hub height is $91.7 \mathrm{~m}$. A rated rotational speed is chosen to $1547 \mathrm{rpm}$ and the gearbox ratio is set to 119 .

\subsection{DFIG EMT model of the electrical drive train}

The electrical drivetrain consists of a two-winding transformer, a doubly fed induction machine, a grid filter, and a partial-scale back-to-back converter. In detail, the back-toback converter itself consists of the machine side converter (MSC), a DC link with chopper and the grid side converter (GSC). The partial-scale converter controls the rotor of the machine so that the stator of the machine, which is directly connected to the grid, will supply the current with nominal grid frequency of $50 \mathrm{~Hz}$. Therefore, up to one third of the power is fed by the GSC over the DC link to the MSC or vice versa. In over-synchronous speed range of the generator the GSC will fed current to the grid. In under-synchronous speed range of the generator the GSC will 
consume current of the grid. The generator has two pole pairs and a rated speed of $1500 \mathrm{rpm}$.

The model is parameterized according to the $5 \mathrm{MW}$ published by NREL [18]. To simulate the target turbine, this parametrization is down scaled and adapted to a $2.5 \mathrm{MW}$ wind turbine. The transformer has a voltage level of $690 \mathrm{~V}$ at the secondary side and $33 \mathrm{kV}$ at the primary side. The switching frequency of the converter is chosen to $2500 \mathrm{~Hz}$.

\subsection{Converter control}

Grid side control The grid side converter is controlled via vector-oriented control [19]. The measured currents are calculated with park transformation to dq values and dq axes, respectively. These currents are compared to the reference values and controlled via PI controller. Therefore, the DC link voltage is controlled by a PI controller and define the reference value for the $\mathrm{d}$ axis of the vector-oriented control. Due to simplification of the model the $q$ axis is set to a constant value. The $d$ and $q$ axis are decoupled via cross coupling to ensure that both the axis can be changed independently from each other. In case of an unsymmetrical fault negative sequence values of the measured currents occur. In order to reduce the negative sequence currents, the negative sequence currents are controlled to zero.

DC link chopper The DC link chopper is activated when an upper boundary of the DC link voltage is reached to protect the Insulated Gate Bipolar Transistors (IGBT). In this case the chopper will lower the DC link voltage by reducing the DC link energy. Therefore, the DC link is short circuited over a resistance within a short time. The DC link chopper is deactivated when a lower boundary of the DC link voltage is reached. The nominal voltage of the DC link is set to $1300 \mathrm{~V}$.

Machine side control The machine side converter is also vector oriented controlled [19]. To increase the voltage in case of a LVRT event, the reactive current reference is defined by continuous voltage control, where the voltage depth is multiplied by a gain factor. This reference value is set to the $d$ axis of the vector controller. The torque reference value is adapted to a current reference value and set to the $\mathrm{q}$ axis. A similar negative sequence control and cross coupling calculation to the grid side control is used in the machine side controller.

\subsection{Pitch- and torque-controller}

The goal of the pitch- and torque controller is safe and stable operation to provide electrical energy. To achieve this, the speed of the rotor must be controlled. The control variables are represented by the pitch movement of the rotor blades and the variable generator torque. However, the wind speed (disturbance variable) is difficult to measure and the aerodynamic behavior of the wind turbine is not linear. The control system has a significant impact on the load of the wind turbine [20].

Control of wind turbines is divided into 4 main regions. Region 1 represents the standstill area below the minimum wind speed. No power is provided. In region 1.5 the transition from a standstill to production and vice versa takes place. Maximizing the power is the goal of region 2, which is realized by a nonlinear control of the generator torque. In region 3 the nominal power of the plant is reached, so that the power is controlled by pitch movement. Due to the non-linear behavior of the rotor, the pitch control must be adjusted by gain scheduling. In region 4 the wind speed has reached the maximum operating speed and the turbine is shut down [21].

Additionally, the controller contains a fault mechanism based on [22], which is trigger by electrical fault or grid loss. This is modelled as state machine. A switch of states is triggered by a drop of the grid voltage level below $85 \%$. The grid voltage level gives the ratio of the current grid level to the setpoint of the grid voltage level. The wind turbine controller reacts immediately by reducing the generator torque to the grid voltage level and increasing the pitch angle for over speed protection. If the grid voltage level remains at a low value for longer than $0.5 s$, the wind turbine is shut down. In the case, that the grid voltage level rises above $85 \%$, the wind turbine controller returns to normal operation mode by ramping up the generator torque and transitioning the pitch angle to its nominal value, after generator speed oscillations have reduced. Other grid faults are not implemented at this point.

\section{Simulation cases}

This paper investigates the influence of a detailed generator model on the wind turbine dynamics and the resulting loads. By including a detailed generator model, the dynamics of the generator, converter and grid interaction is included in the holistic approach, rather than using direct application of the commanded generator torque from the wind turbine controller as it is common in wind turbine load analysis.

As mentioned in Sect. 2.1, the usual aero-elastic load simulation tool does not contain a detailed electrical model. For the comparison, all simulations are performed with the holistic wind turbine model, referenced as holistic in the following, and a simple model. In the simple model the right-hand site of Fig. 1 (including the DFIG generator, DC link, chopper, transformer, grid and controllers for electrical 
components) is replaced by rotational inertia and a simple equation for the electrical power as

$P_{E}=\omega \cdot \tau$,

where $\omega$ is the generator speed and $\tau$ is the electromagnetic torque, which is equal to the generator torque reference from the wind turbine controller. The generator torque command from the controller is directly applied to the generator inertia and therefore the simple model does not show the detailed dynamic behavior.

The performed simulations are based on DLC 2.3 and DLC 2.4 from IEC Standard [1]. In DLC 2.3 an extreme operating gust (EOG) with a simultaneous grid loss is simulated. The grid loss is triggered at the first rising inflection point of the EOG profile to induce maximum loads on the wind turbine. For DLC 2.3, the simulated wind speeds are $8.65,12.65$ and $21.5 \frac{\mathrm{m}}{\mathrm{s}}$. In contrast to the previous described case, only a temporal grid fault occurs in DLC 2.4 after which the turbine remains in operation in turbulent wind. In this study, the grid fault is chosen to be a LVRT on all 3 phases for the duration of $0.5 s$. DLC 2.4 is simulated at wind speeds of $7.45,11.65$ and $21.5 \frac{\mathrm{m}}{\mathrm{s}}$.

Fig. 2 Grid voltage level and chopper behavior for the holistic model during the LVRT during turbulent wind of $11.65 \frac{\mathrm{m}}{\mathrm{s}}$. The blue line shows the occurrence of the grid fault

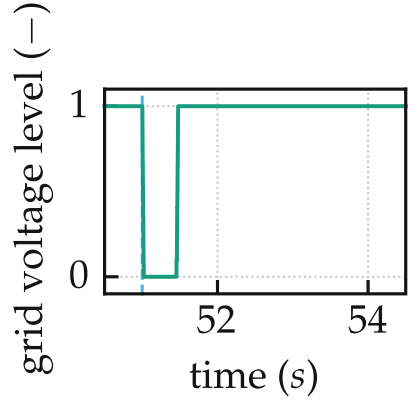

Fig. 3 Comparison of wind turbine response to LVRT between simple and holistic model with turbulent wind of $11.65 \frac{\mathrm{m}}{\mathrm{s}}$. The blue line shows the occurrence of the grid fault
The grid faults in the simulation are physically modelled by short circuit of all phases in the grid component of the holistic model. In case of the simple model, the grid fault is emulated by altering the grid voltage level signal for the controller.

\section{Results of ultimate load cases}

In DLC 2.4 the occurrence of a LVRT in nominal operation is simulated. Fig. 2 shows the response of the detailed electrical system. The grid fault occurs at $51 s$ and the grid voltage level drops to $1 \%$.

During the grid fault, the voltage in the DC link increases, which triggers the chopper mechanism multiple times. In total, $74.4 \mathrm{kWs}$ are consumed by the chopper. In Fig. 3, the corresponding system response is shown and compared between the simple and holistic model.

Due to the detection of the grid fault by the wind turbine controller, the generator (gen.) torque is immediately ramped down. The holistic model shows increased oscillation in multiple components, especially in the generator torque. This causes high twisting of the drivetrain (dt.) and generator speed. These oscillations effected the pitch
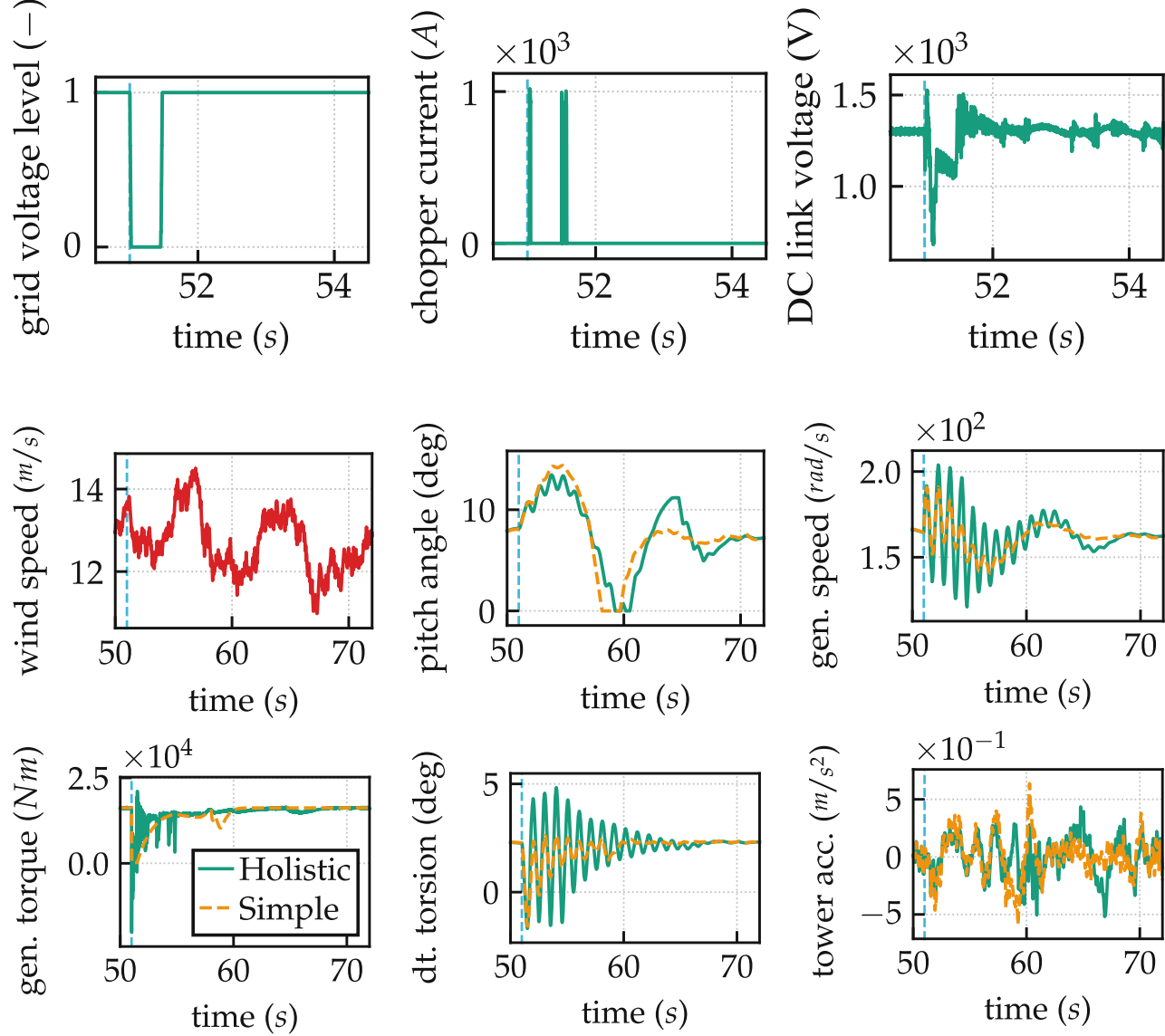
Table 1 Wind turbine load changes from simple to the holistic model for DLC 2.4

\begin{tabular}{|c|c|c|c|c|c|c|c|c|}
\hline \multirow{2}{*}{$\begin{array}{l}\text { DLC } 2.4 \\
\text { Load Component }\end{array}$} & \multicolumn{4}{|c|}{ Absolute change } & \multicolumn{4}{|c|}{ Proportional change (\%) } \\
\hline & Span & $\operatorname{Max}$ & Mean & Std & Span & Max & Mean & Std \\
\hline Generator speed (rpm) & 493 & 204 & -2 & 115 & 125 & 11 & -0.07 & 215 \\
\hline Generator torque (kNm) & 25.3 & 4.8 & 0.2 & 0.1 & 157 & 29.8 & 1.46 & 3.37 \\
\hline $\begin{array}{l}\text { Blade in-plane bending moment } \\
(\mathrm{kNm})\end{array}$ & 763 & 468 & 8.2 & 50.4 & 18.7 & 19.7 & 1.5 & 4.3 \\
\hline $\begin{array}{l}\text { Blade out-plane bending moment } \\
(\mathrm{kNm})\end{array}$ & 336 & 600 & 2.3 & 29.3 & 11.3 & 12.4 & 0.9 & 5.3 \\
\hline Blade tip out-of-plane deflection (m) & 0.1 & 0.1 & 0.02 & 0.03 & 2.4 & 5.6 & 75.8 & 3.3 \\
\hline Blade tip in-plane deflection (m) & 0.1 & 0.05 & 0.07 & 0.01 & 4.6 & 3.1 & 88.7 & 3.4 \\
\hline Drivetrain torsion (deg) & 3.4 & 2.7 & 0.03 & 0.92 & 79 & 101 & 1.5 & 164 \\
\hline $\begin{array}{l}\text { Tower bottom fore-aft moment } \\
(\mathrm{kNm})\end{array}$ & 281 & 1404 & 237 & 68.8 & 2.84 & 6.6 & 1.0 & 2.5 \\
\hline $\begin{array}{l}\text { Tower bottom side-side moment } \\
(\mathrm{kNm})\end{array}$ & 386 & 363 & 319 & 72.8 & 7.4 & 8.1 & 1.6 & 7.6 \\
\hline
\end{tabular}

Table 2 Wind turbine relative load changes from simple to the holistic model for DLC 2.3

\begin{tabular}{|c|c|c|c|c|c|c|c|c|}
\hline \multirow{2}{*}{$\begin{array}{l}\text { DLC } 2.3 \\
\text { Load Component }\end{array}$} & \multicolumn{4}{|c|}{ Absolute change } & \multicolumn{4}{|c|}{ Proportional change (\%) } \\
\hline & Span & $\operatorname{Max}$ & Mean & Std & Span & $\operatorname{Max}$ & Mean & Std \\
\hline Generator speed (rpm) & 0.5 & 0.34 & 2.2 & 1.6 & 0.02 & 0.02 & 0.35 & 0.22 \\
\hline $\begin{array}{l}\text { Blade in-plane bending moment } \\
(\mathrm{kNm})\end{array}$ & -20 & 36.0 & -0.35 & 1.2 & -0.5 & 1.7 & 4.0 & 0.12 \\
\hline $\begin{array}{l}\text { Blade out-of-plane bending moment } \\
(\mathrm{kNm})\end{array}$ & 14.5 & 13.2 & 2.5 & 7.5 & 0.1 & 0.2 & 1.1 & 0.5 \\
\hline Blade tip out-of-plane deflection (m) & 0.02 & 0.02 & 0.0 & 0.01 & 0.2 & 0.6 & 0.01 & 0.72 \\
\hline Blade tip in-plane deflection (m) & 0.02 & 0.02 & 0.0 & 0.0 & 0.6 & 0.6 & 0.3 & 0.2 \\
\hline Drivetrain torsion (deg) & -0.02 & -0.02 & 0.0 & 0.0 & -0.5 & -0.6 & 6.0 & -0.6 \\
\hline Tower bottom fore-aft moment $(\mathrm{kNm})$ & 331 & 424 & 27 & 40.4 & 0.2 & 0.9 & 21.83 & 0.2 \\
\hline $\begin{array}{l}\text { Tower bottom side-side moment } \\
(\mathrm{kNm})\end{array}$ & 197 & 103 & 18 & 69 & 3.7 & 4.2 & 11.8 & 4.7 \\
\hline
\end{tabular}

controller as well, as it can be seen in the increase pitch fluctuations for the holistic model. The tower acceleration (acc.) is higher in the simple model. Which indicates that a detailed generator model also effects the distribution of loads. Overall, both models remain in operation in turbulent wind, whereas the simple model reaches the normal operation mode earlier.

A comprehensive evaluation is presented in the following Tables 1 und 2, which show the change of load components between the simple and holistic model. The mean, standard deviation (std), maximum (max) value and the range between maximum and minimum value (span) are calculated for all components for a time span of $25 s$ after the occurrence of the grid fault. All changes are computed as absolute and proportional value, where the simple model is used as reference. The absolute values are displayed with the corresponding unit and the proportional values as percentage. For the evaluation, all wind speeds are considered.

The highest change occurs for the drivetrain torsion, generator speed and torque. A massive increase in span of up to $125 \%$ and max of up to $101.3 \%$ is observed. Addition- ally, blade loads are increased as well by up to $18 \%$ in the holistic model. The tower loads are affected by the detailed generator model as well, where the side-side bending moment shows the largest rise. Changes in the mean value are not significant. It should be noted that the blade deflection mean value is close to zero and therefore shows a high proportional change, which is not significant. The standard deviation indicates increased oscillations in the drivetrain components.

In DLC 2.3 a total loss of the grid connection during an EOG event occurs, which cause the wind turbine operational controller to perform a shutdown (Fig. 4).

The results for DLC 2.3 show less differences between the simple and holistic model. Since the fault duration is larger than $0.5 \mathrm{~s}$, the wind turbine controller switches to shutdown mode and after $25 s$ the wind turbine approaches a stand still.

Table 2 shows the dominating absolute and proportional changes in the same way as Table 1 for all wind speed of the investigated DLC 2.3. 
Fig. 4 Wind turbine response to grid loss during EOG at 12.65 "m"/"s". The blue line fault shows the occurrence of the grid
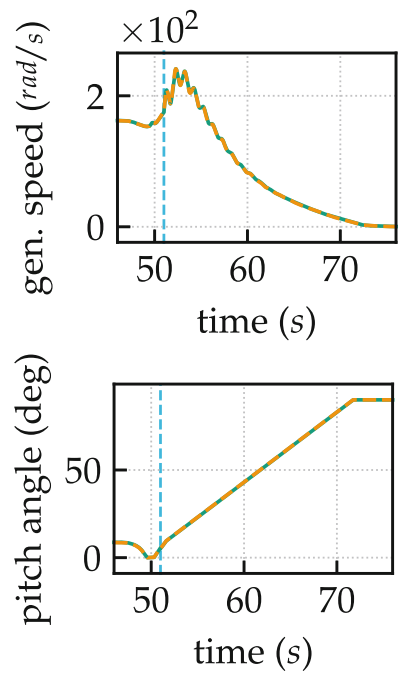

The overall results show little difference between the models. Only one increase in the side-side tower bending moment is observed. In the short interval of $0.5 s$ between grid loss and initiation of the shutdown of the wind turbine, a detailed generator model has little effect on the simulation results.

\section{Discussion and conclusion}

In this paper, a holistic wind turbine model with detailed aero-elastic and electrical model is presented. The model is compared against the classical aero-elastic model without detailed generator and grid interaction in load calculation simulations according to the IEC Standard.

After all, results of load calculations show that the load distribution changes. The generator torque of the holistic model shows higher dynamic behavior, which leads to increased loads on the gearbox. In this case, the tower and blades are affected as well. In addition, the simulations show that the complex interaction of the generator, converter control and grid dynamics should not be neglected in simulations, where the wind turbine is remaining in operation. The dynamics of the interaction of the electrical model and drivetrain may influence the fatigue life for wind turbine components, which should be further investigated.

Additionally, a holistic model can be used for further studying of wind turbine controllers in the context of grid faults. Moreover, the presented approach could be used for holistic wind park modelling with interaction on the electrical side and simultaneous evaluation of load on single wind turbine components.

Funding Open Access funding enabled and organized by Projekt DEAL.
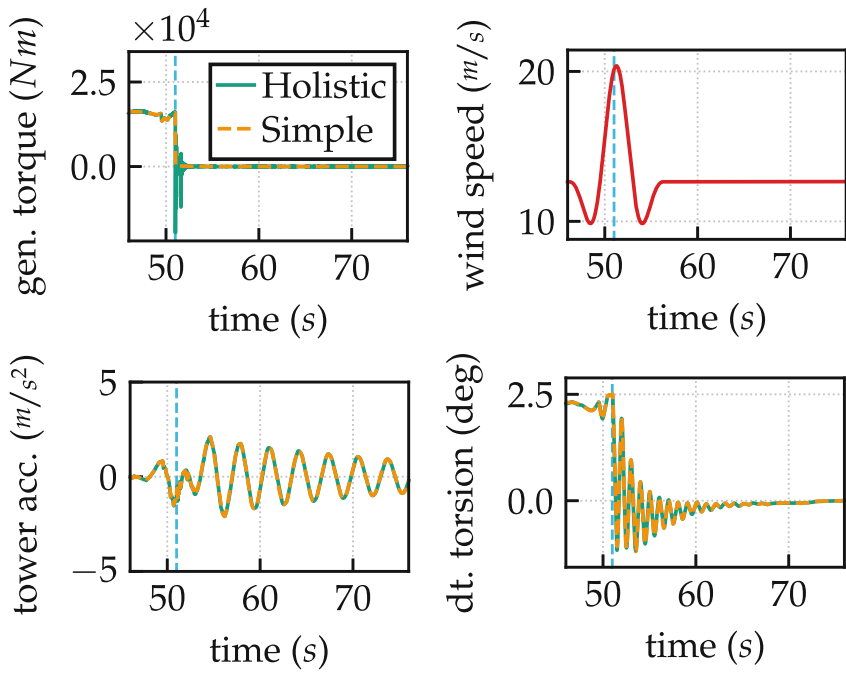

Open Access This article is licensed under a Creative Commons Attribution 4.0 International License, which permits use, sharing, adaptation, distribution and reproduction in any medium or format, as long as you give appropriate credit to the original author(s) and the source, provide a link to the Creative Commons licence, and indicate if changes were made. The images or other third party material in this article are included in the article's Creative Commons licence, unless indicated otherwise in a credit line to the material. If material is not included in the article's Creative Commons licence and your intended use is not permitted by statutory regulation or exceeds the permitted use, you will need to obtain permission directly from the copyright holder. To view a copy of this licence, visit http://creativecommons.org/licenses/by/4. $0 \%$

\section{References}

1. IEC, "IEC 61400-1: Wind Turbines-Part 1: Design Requirements," 2019.

2. Gomes C, Thule C, Broman D, Larsen P, Vangheluwe H (2017) Cosimulation: state of the art. Technical Report. ArXiv. https://arxiv. org/pdf/1702.00686v1.pdf

3. Singh M, Muljadi E, Jonkman J, Gevorgian V (2014) Simulation for wind turbine generators-with FAST and MATLAB-Simulink modules. National Renewable Energy Laboratory,

4. Yingying W, Qing L, Shiyao Q (2014) A new method of wind turbines modeling based on combined simulation. International Conference on Power System Technology (POWERCON 2014).

5. Singh M, Muljadi E, Jonkman J (2013) Hybrid electro-mechanical simulation tool for wind turbine generators. IEEE Green Technologies Conference.

6. Krajinski P, Chhor J, Kipke V, Sourkounis C (2019) Modeling and simulation study of a DFIG wind turbine in a 3D wind field during startup and wind speed changes. IECON 2019-45th Annual Conference of the IEEE Industrial Electronics Society, pp 2408-2415

7. Chhor J, Tourou P, Günther K, Kipke V, Einwächter F, Sourkounis C (2019) Smart Windpark laboratory: infrastructure for application-oriented wind energy research. IEEE International Conference 2019, pp 697-703

8. Elmqvist H, Otter M, Cellier FE (1995) Inline integration: a new mixed symbolic/numeric approach for solving differential-algebraic equation systems. Proceedings of ESM'95, European Simulation Multiconference. 
9. Wilfahrt U, Hillmann C, Samlaus R, Thomas P (2015) Projekt OneWind (Phase 2): Schlussbericht. Technische Informationsbibliothek Universitätsbibliothek Hannover und Technische Informationsbibliothek (TIB). https://doi.org/10.2314/GBV:848363280

10. Strobel M, Vorpahl F, Hillmann C, Gu X, Zuga A, Wihlfahrt U (2011) The on-wind modelica library for offshore wind turbines-implementation and first results. Proceedings of the 8th International Modelica Conference, pp 603-609

11. Leimeister M, Thomas P (2017) The onewind modelica library for floating off-shore wind turbine simulations with flexible structures. Proceedings of the 12th International Modelica Conference, pp 633-642

12. Leimeister M (2019) Python-modelica framework for automated simulation and optimization. Proccedings of the 13th International Modelica Conference, pp 51-58

13. Leimeister M, Kolios A, Collu M, Thomas P (2019) Larger MWclass floater de-signs without upscaling? - a direct optimization approach. Proccedings of the ASME 2019 38th International Conference on Ocean Offhsore and Arctic Engineering.

14. Feja P, Huhn M (2019) Real time simulation of wind turbines for hiL testing with MoWiT

15. Jersch T (2018) Dynalabupdate: meeting industry needs and standardization \& Hil-Grid-cop: generator and converter testing. 5th
Annual International Workshop on Grid Simulator Testing of Energy Systems and Wind Turbine Powertrains.

16. Neshati M, Zuga A, Jersch T, Wenske J (2016) Hardware-in-theloop drive train control for realistic emulation of rotor torque in a full-scale wind turbine na-celle test. European Control Conference.

17. Thomas P, Gu X, Samlaus R, Hillmann C, Wihlfahrt U (2014) The onewind Modelica library for wind turbine simulation with flexible structure-modal reduction method in Modelica. Proceedings of the 10th International 2014, pp 939-948

18. Jonkman J, Butterfield S, Musial W, Scott G (2009) Definition of a 5-MW reference wind turbine for offshore system development

19. Wu B, Lang Y, Zargari N, Kouro S (2011) Power conversion and control of wind energy

20. Burton T, Jenkins N, Sharpe D, Bossanyi E (2011) Wind energy handbook. John Wiley \& Sons,

21. Njiri JG, Söffker D (2016) State-of-the-art in wind turbine control: trends and challenges. Renewable and Sustainable Energy Reviews 60, pp 377-393. https://doi.org/10.1016/j.rser.2016.01.110

22. Thet AK, Saitoh H (2009) Pitch control for improving the low-voltage ride-through of wind farm. Transmission \& Distribution Conference. 